\title{
Validación de una escala de percepciones acerca del estatus jurídico atribuido a los animales no humanos
}

\author{
Israel González Marino \\ Universidad Central de Chile, Región de Coquimbo, Chile \\ israel.gonzalez@ucentral.cl \\ Master en Derecho Animal y Sociedad (UAB) \\ ORCID: 0000-0002-8769-4425
}

Carmen Gloria Covarrubias Apablaza

Universidad Central de Chile, Chile

carmen.covarrubias@ucentral.cl

Doctora en Psicología Escolar y Desarrollo

ORCID: 0000-0002-5982-849X

Hedy Acosta Antognoni

Universidad de Talca, Chile

hacosta@utalca.cl

Doctora en Psicología del Trabajo, de las Organizaciones y en RRHH

ORCID: 0000-0002-8412-4128

Recepción: Agosto 2021

Aceptación: Septiembre 2021

Cita recomendada. GONZÁLEZ MARINO I., COVARRUBIAS APABLAZA, CG, ACOSTA ANTOGNONI, H., Validación de una escala de percepciones acerca del estatus jurídico atribuido a los animales no humanos, dA. Derecho Animal (Forum of Animal Law Studies) 12/3 (2021). - DOI https://doi.org/10.5565/rev/da.586

Resumen

La revisión de la literatura muestra un amplio desarrollo teórico acerca de los enfoques de regulación y protección jurídica de los animales no humanos, así como del estatus jurídico que se les atribuye. No obstante, las investigaciones que indagan en las actitudes y percepciones de la comunidad en relación a dicha temática constituyen un área incipiente de exploración. Este estudio tiene por objetivo diseñar y validar una escala de percepciones acerca del estatus jurídico atribuido a los animales no humanos. Para ello, se sigue una metodología cuantitativa, de tipo exploratoria-descriptiva, no experimental y transversal. La muestra estuvo compuesta por 639 sujetos, los que responden un instrumento de 26 ítems distribuidos en tres variables: a) percepciones ético-jurídicas acerca de los animales no humanos en general, b) percepciones acerca de los derechos de los animales no humanos según su destino atribuido, y c) aceptación de la satisfacción de necesidades humanas según destino distribuido a animales no humanos. Los análisis a los datos revelaron fiabilidades de .84, .97 y .90, así como explicaciones de varianza de $54,3 \%, 83,1 \%$ y $56,7 \%$ para cada una de las variables de la escala. Se concluye que la escala es original y novedosa, además de válida y fiable para evaluar las percepciones que tiene la comunidad con respecto al estatus jurídico atribuido a los animales no humanos. Se discuten implicancias y prácticas del estudio.

Palabras clave: estatus jurídico; animales no humanos; percepciones; escala de percepciones. 


\section{Abstract - Validation of a scale of perceptions about the legal status attributed to non-human animals}

The review of the literature shows broad theoretical development in the approaches of the regulatory and legal protection of non-human animals, as well as of the legal status attributed to them. However, research that investigates the community's attitudes and perceptions in relation to this issue constitutes an incipient area of exploration. The objective of this study is to design and validate a scale of perceptions about the legal status attributed to non-human animals. To do this, a quantitative, exploratory-descriptive, non-experimental and cross-sectional methodology is followed. The sample consisted of 639 subjects, who answered an instrument of 26 items distributed in three variables: a) ethical-legal perceptions about non-human animals in general, b) perceptions about the rights of non-human animals according to their attributed use, and c) acceptance of the satisfaction of human needs according to the use attributed to non-human animals. The analyses of the data revealed reliabilities of $.84, .97$ and .90 , as well as explanations of variance of $54.3 \%, 83.1 \%$ and $56.7 \%$ for each of the scale variables. It is concluded that the scale is original and novel, as well as valid and reliable to evaluate community perceptions on the legal status attributed to non-human animals. Implications and practices of the study are discussed.

Keywords: legal status; non-human animals; perceptions; scale of perceptions.

\section{Sumario:}

1. Introducción

2. Marco teórico

3. Método

4. Análisis de resultados

5. Discusión

6. Conclusiones

Bibliografía

Anexo

\section{Introducción}

Desde los tiempos de Roma, un ente podía ser considerado como una persona o una cosa. La diferencia fundamental entre una y otra radica en que las personas son las únicas que pueden ser titulares de derechos, mientras que las cosas no, e incluso, sus intereses más fundamentales carecen de protección segura y adecuada ${ }^{1}$. Históricamente, los demás animales -los no humanos- han sido ubicados jurídicamente en este segundo grupo, una herencia del Derecho Romano que se ha perpetuado hasta nuestros días, y cuya explicación estaría dada por la falta de un verdadero debate social y urgencia política ${ }^{2}$.

La protección que damos a los demás animales es un tema que progresivamente ha ido cobrando mayor importancia en las distintas esferas del quehacer humano ${ }^{3}$. De ahí que se han desarrollado diversas leyes que procuran la protección de estos seres vivos, castigando actos de crueldad o maltrato en su contra ${ }^{4}$. Sin embargo, su regulación jurídica, de forma más o menos generalizada, preserva el estatus de propiedad y configura un umbral de bienestar para validar prácticas sistemáticas de explotación ${ }^{5}$.

Lo anterior podría deberse a que, como explica HORTA, cuando hay injusticias generalizadas, estas se

\footnotetext{
${ }^{1}$ WISE, S., Sacudiendo la jaula: hacia los derechos de los animales (Valencia 2018), 13.

${ }^{2}$ GIMÉNEZ-CANDELA, T., Introducción, en Animales y Derecho (Valencia, 2015), 12.

3 GONZÁLEZ MARINO, I., Animales no humanos como sujetos ante el Derecho y limitaciones al ejercicio de derechos fundamentales: algunos desafíos a propósito de la jurisprudencia reciente, en Discusiones y desafíos en torno al Derecho Animal (Santiago 2018), 69.

${ }^{4}$ CORRAL TALCIANI, H., Curso de Derecho Civil: parte general (Santiago 2018), 263.

${ }^{5}$ GALLEGO SAADE, J., Sobre la posibilidad de un 'Derecho Animal', en Derecho Animal: teoría y práctica (Santiago 2018 ), 180.
} 
vuelven difíciles de reconocer. Así, no es raro que quienes se benefician de ellas las consideran totalmente justificadas. Sin embargo, el autor invita a recordar que las sociedades evolucionan y las injusticias pueden ir siendo progresivamente cuestionadas ${ }^{6}$. En este contexto, las opiniones científicas, filosóficas y culturales sobre los demás animales han cambiado debido a los aportes teóricos de autores como SINGER ${ }^{7}, \mathrm{REGAN}^{8}$, FRANCIONE $^{9}$ y NUSSBAUM ${ }^{10}$, entre muchos otros y otras, en función de los hallazgos en materia de sintiencia animal ${ }^{11}$.

Los desarrollos teóricos a propósito de la relevancia ética de los demás animales han llevado a parte de la doctrina a estimar como sensato reconsiderar la idoneidad del estatuto de propiedad aplicado a ellos ${ }^{12}$. En efecto, se ha planteado que existiría cierta popularidad acerca de un eventual cambio del estatus jurídico para, al menos, algunos de los demás animales, sin embargo, también se ha advertido la escasez de investigaciones empíricas al respecto ${ }^{13}$. Así, a partir de una revisión de la literatura existente, SHYAM ha resaltado la necesidad de comprender mejor los valores y opiniones de la comunidad acerca de la situación legal de los demás animales. Dicha investigación empírica -indica- podría proporcionar una mejor idea acerca de la factibilidad política de un cambio en su estatus jurídico. La autora también apunta como necesario determinar si los estatutos legales alternativos propuestos por los teóricos disfrutan de apoyo en la comunidad. Estos datos pueden, en última instancia, agregar fuerza a los argumentos para promover un cambio de este tipo, pero además pueden orientar a la doctrina y guiar la agenda educativa de grupos animalistas ${ }^{14}$. Por lo anterior, con este estudio se pretende responder a la necesidad descrita, aportando con una escala original y novedosa -que hasta hoy no existe-, que permita evaluar las percepciones de la comunidad acerca del estatus jurídico atribuido a los demás animales. Esto resulta clave no solo para el diálogo sostenido entre Derecho y sociedad, sino que además para las políticas y programas que comienzan a ocupar cada vez más espacios en la agenda del Derecho Animal.

El objetivo de este trabajo es, entonces, diseñar y validar una escala de percepciones acerca del estatus jurídico atribuido a los animales no humanos. Para ello, se optó por una metodología cuantitativa, de tipo exploratoria-descriptiva y con una recolección de datos de corte transversal. De esta manera, se contribuye desde lo teórico al generar un instrumento que permita recoger las percepciones de la comunidad acerca del estatus jurídico atribuido a los animales no humanos. Asimismo, en cuanto a lo metodológico, constituye un aporte inédito a la medición de un constructo, cumpliendo con estándares de validez y fiabilidad. Por último, en lo práctico, permite aportar datos para reforzar las discusiones de las agendas políticas y jurídicas en cuanto a la problemática animal. A continuación, se desarrollan los aspectos teóricos que dan cuenta de los principales enfoques de Derecho Animal y los estatus jurídicos que se han atribuido a los animales no humanos. Luego, se explicita el método que ha adoptado en este estudio, sus resultados, discusiones y conclusiones.

\section{Marco teórico}

\subsection{Enfoques de Derecho Animal}

En la historia del pensamiento occidental, las reflexiones filosóficas sobre si los demás animales son o no titulares de derechos son muy variadas, sin embargo, POCAR las resume en tres posturas principales que reconducen a las siguientes afirmaciones: a) los demás animales no son seres sintientes, de manera que no pueden ser titulares de derechos ni objeto de obligaciones para los humanos; b) los demás animales son seres sintientes, por tanto, aun no pudiendo ser titulares de derechos propios, pueden ser objeto de obligaciones frente a los humanos; y c) los demás animales son seres sintientes, por ende, son sujetos de derechos propios y objetos de deber frente a los humanos ${ }^{15}$. La primera postura se puede identificar con un enfoque clásico o tradicional, la segunda con un enfoque bienestarista, y la tercera con un enfoque abolicionista, revisadas a continuación.

\footnotetext{
${ }^{6}$ HORTA, O., Un paso adelante en defensa de los animales (Madrid 2017), 200.

${ }^{7}$ SINGER, P., Animal Liberation: a new ethics for our treatment of animals (New York 1975).

${ }^{8}$ REGAN, T., The Case for Animal Rights (Berkeley 1983).

${ }^{9}$ FRANCIONE, G., Animals, Property, and the Law (Philadelphia 1995).

${ }^{10}$ NUSSBAUM, M. C., Frontiers of Justice (Cambridge 2006).

${ }^{11}$ BEKOFF, M y MEANEY, C. A., Encyclopedia of animal rights and animal welfare (Connecticut 1998).

12 Op. cit. FRANCIONE (1995); FRANCIONE, G. Animals-Property or Persons?, en Rutgers Law School (Newark) Faculty Papers, working paper 21 (2004).

13 SHYAM, G., The legal status of animals: the world rethinks its position, en Alternative Law Journal 40/4 (2015). https://doi.org/10.1177/1037969X1504000411

${ }^{14}$ SHYAM, G., How community attitudes can strengthen arguments for changing the legal status of animals. En Society Register $3 / 3$ (2019), 68-74. https://doi.org/10.14746/sr.2019.3.3.04

${ }^{15}$ POCAR, M., Los animales no humanos. Por una sociología de los derechos (Buenos Aires 2013), 28.
} 


\subsubsection{Enfoque clásico o tradicional}

POCAR explica que la concepción antropocéntrica del mundo, de la que derivan la afirmación de la prioridad de los humanos respecto de todo otro ser viviente, así como la del pretendido derecho de los humanos al dominio del mundo, tiene orígenes tan antiguos que no pueden ser rastreados. Tal concepción se funda, principalmente, sobre dos presupuestos asumidos como hechos, de los que se desprende la especial dignidad de los humanos respecto de todo otro ser viviente: 1) por sobre todas las cosas, que sólo los humanos están dotados de alma; y 2) que sólo los humanos poseen capacidad de raciocinio. Ello estaría sustentado por la doctrina de DESCARTES, según la cual los demás animales, dado que no razonarían ni estarían en condiciones de expresar en modo inteligente un pensamiento, serían una especie de máquinas incapaces de sentir y, por tanto, ningún derecho se les podría reconocer, ni ninguna obligación hacia ellos por parte de los seres humanos podría ser establecida ${ }^{16}$. De ahí que las éticas tradicionales sólo permitían evaluar moralmente las acciones humanas que afectan, directa o indirectamente, a los seres humanos, mientras que en los actos que afectan a los demás animales se admitía que el ser humano podía guiarse totalmente por sus propios intereses ${ }^{17}$.

De acuerdo con este enfoque, los demás animales carecen de estatus moral y los humanos no tendríamos deberes hacia ellos. Incluso, los intereses humanos más nimios se sobreponen a los intereses de lo no humanos ${ }^{18}$. Así, en términos prácticos, si se debe elegir entre el respeto a los derechos fundamentales de las personas y la preservación de una cosa, por muy valiosa que ésta sea, ha de prevalecer lo primero ${ }^{19}$.

\subsubsection{Enfoque bienestarista o Welfarism}

Gracias a los avances y estudios científicos, en las últimas décadas se ha podido evidenciar que, además de los seres humanos, un inmenso número de otros animales pueden sufrir y disfrutar, con lo que se descarta la idea de que serían objetos inconscientes ${ }^{20} \mathrm{y}$, por el contrario, serían seres sintientes. La sintiencia es un término que se refiere a tener la consciencia y la capacidad cognitiva mental necesarias para tener emociones y experiencias subjetivas. Esto significa que los seres sintientes no sólo detectan, observan y reaccionan a las cosas que les rodean, sino que también pueden sentir o experimentar algo en respuesta ${ }^{21}$.

El enfoque bienestarista reconoce que, efectivamente, un gran número de animales no humanos son seres sintientes que pueden experimentar dolor y, por tanto, existe un interés en evitarles sufrimientos innecesarios, aunque sí podrían ser utilizados para satisfacer necesidades humanas ${ }^{22}$. En tal sentido, este enfoque postula que podemos usar o explotar económicamente a los demás animales, siempre que se reduzcan los daños o el malestar que se les pueda causar ${ }^{23}$. En otras palabras, este enfoque busca mitigar el dolor y sufrimiento al que se expone a los demás animales, y no la erradicación o supresión de las distintas prácticas de explotación a las que se les somete ${ }^{24}$. De ahí que se ha afirmado que la posición de bienestarista se centra en el tratamiento de los demás animales, y no en su uso propiamente $\operatorname{tal}^{25}$. Lo anterior se explicaría pues, para esta postura, los demás animales tendrían un estatus moral menos importante que el de los seres humanos, lo que se traduce en que sus vidas o libertades representan siempre una categoría inferior ${ }^{26}$.

En términos jurídicos, el enfoque bienestarista se refleja en estatutos anticrueldad y otras leyes que imponen obligaciones de tratar "humanitariamente" a los demás animales ${ }^{27}$, sin cuestionar su estatus de

\footnotetext{
16 Ibíd., 29-33.

17 SÁNCHEZ GONZÁLEZ, M. A., El debate ético actual sobre la relación del hombre con los animales, en Los derechos de los animales (Madrid 2002), 110.

${ }^{18}$ LEYTON DONOSO, F., Los animales en la bioética: tensión en las fronteras del antropocentrismo (Barcelona 2019 ), 50.

${ }^{19}$ Op. cit. CORRAL TALCIANI (2018) 265.

${ }^{20}$ Op. cit. HORTA (2017) 41.

${ }^{21}$ COMPASSION IN WORLD FARMING, Por qué el bienestar de los peces es importante: la evidencia de la sintiencia en peces (Madrid 2020), 2.

${ }^{22}$ FRANCIONE, G. L. y GARNER, R., Introduction en The animal rights debate: abolition or regulation? (New York 2010) ix-xii; SERRA PALAO, P., La incorporación de la ética animal al derecho, en Bioderecho.Es 7 (2019), 4. https://doi.org/10.6018/bioderecho.364561; RÚA SERNA, J. C., De garras y de guerras: reflexiones sobre el uso de los animales en el ejercicio legal de la seguridad armada desde una visión abolicionista (Medellín 2017), 50-51.

${ }^{23}$ HORTA, O., Ética y animales no humanos: conceptos básicos, en Manual de Derecho Animal (Buenos Aires 2019), 53-56; COTELO, S., Veganismo: de la teoría a la acción (Madrid 2013), 113.

24 SALAZAR, M. A. Activismo pragmático: animalismo y políticas públicas, en Reflexión Política 21/41 (2019), 69. https://doi.org/10.29375/01240781.3283; JIMÉNEZ CHAMORRO, J. M., Biodiversidad y veterinaria, ante el animalismo: parte II, Animalismo y veterinaria, en Badajoz Veterinaria 12 (2018), 74.

${ }^{25}$ FRANCIONE, G. L. y CHARLTON, A., Animal rights: the abolitionist approach (Lexington 2015), 32.

${ }^{26}$ Op. cit. LEYTON DONOSO (2019) 50.

${ }^{27}$ Op. cit. FRANCIONE y GARNER (2010) ix.
} 
propiedad $^{28}$. En este sentido, el bienestarismo respalda la reforma progresiva de las leyes de protección animal existentes, sin alterar radicalmente el status quo ${ }^{29}$. Por ello, se ha dicho que las leyes bienestaristas no vienen a terminar, en principio, con la explotación animal, sino que buscan que mientras sean utilizados, sufran lo menos posible ${ }^{30}$.

En términos prácticos, el enfoque bienestarista defiende que, en determinados contextos, los animales no humanos destinados al consumo sean "sacrificados" siempre y cuando ello se realice bajo condiciones de "calidad", "muerte digna" y "sufrimiento mínimo". Asimismo, aceptaría que los demás animales estén en zoológicos, si se les brindan los cuidados óptimos para su habitabilidad"

Se ha criticado este enfoque por responder a una visión antropocéntrica del mundo, defendiendo la utilización y el trato "humano" de los demás animales ${ }^{32}$, lo que impediría transformar la consideración egoísta que tendríamos de ellos como un medio para satisfacer nuestros propios intereses ${ }^{33}$. Producto de estas críticas, algunos de sus exponentes han afirmado que quieren terminar por completo con el uso de animales no humanos en algún momento futuro, o, al menos, reducir significativamente el número de animales explotados por humanos, acudiendo a formas de regulación o protección como medio para ese fin. A estas variantes se les suele denominar neobienestarismo o proteccionismo -new welfarism o protectionism- ${ }^{34}$.

A pesar de los matices introducidos por variantes del bienestarismo, se ha criticado que ellas no dejarían de tener como soporte una concepción especista y antropocéntrica del mundo, en la que el uso y hasta la explotación de los demás animales sería aceptada siempre y cuando se materialice bajo unos supuestos de limitación o refinamiento ${ }^{35}$. Estas críticas provienen, principalmente, del denominado enfoque abolicionista.

\subsubsection{Enfoque abolicionista o Abolitionism}

El enfoque abolicionista plantea que no existe justificación moral alguna para usar animales, con independencia del propósito y por muy "humanitariamente" que los tratemos ${ }^{36}$. Por ello, rechaza la estrategia una reforma gradual de su estatus legal y, en su lugar, considera que la abolición del uso de los demás animales por parte de los seres humanos es éticamente deseable y políticamente posible ${ }^{37}$.

El abolicionismo aparece tradicionalmente unido a la supresión de la esclavitud. De esta forma, aplicado a la problemática animal, consistiría en la eliminación total de cualquier tipo de explotación y el cese de su utilización como medios para la satisfacción de fines humanos y, en definitiva, la erradicación de la relación de dominio existente ${ }^{38}$. En otras palabras, postula que si rechazamos la idea de que los demás animales son cosas, debemos reconocer que tienen el derecho fundamental a no ser tratados como propiedad. Esto requiere que rechacemos el uso de animales no humanos para comida, vestuario, entretenimiento, experimentación, etcétera, y que debamos abolir esta explotación institucionalizada ${ }^{39}$.

El objetivo de este enfoque es generar una sociedad de respeto hacia todos los seres sintientes, superando la discriminación por especie -denominada especismo ${ }^{40}$-, otorgar personalidad jurídica a los demás animales y que, en consecuencia, se adopte un estilo de vida vegano ${ }^{41}$. Esto implica imponernos la obligación de respetar las vidas y potenciales formas de florecimiento y desarrollo de estos individuos sintientes ${ }^{42}$.

\subsection{Estatus jurídicos aplicables a los demás animales}

\footnotetext{
${ }^{28}$ GARNER, R., A Defense of a Broad Animal Protectionism, en The animal rights debate: abolition or regulation? (Nueva York 2010), 168.

${ }^{29}$ TIRADO, C. R., La dimensión política de las éticas animales en el contexto de la bioética: problemas de integración y desafíos futuros, en Revista Iberoamericana de Bioética 1 (2016), 4. https://doi.org/10.14422/rib.i01.y2016.005

${ }^{30}$ SERRA, J. I., Experimentación con animales, en Manual de Derecho Animal (Buenos Aires 2019) 295.

${ }^{31}$ Op. cit. SALAZAR (2019) 69.

${ }^{32}$ VÁZQUEZ, R. y VALENCIA, Á., La creciente importancia de los debates antiespecistas en la teoría política contemporánea: del bienestarismo al abolicionismo, en Revista Española de Ciencia Política 42, (2016), 153. https://doi.org/10.21308/recp.42.06

${ }^{33}$ Op. cit. SERRA PALAO (2019) 31.

${ }^{34}$ Op. cit. FRANCIONE y CHARLTON (2015) 33.

${ }^{35}$ Op. cit. VÁZQUEZ y VALENCIA (2016) 157.

${ }^{36}$ Op. cit. FRANCIONE y GARNER (2010) x.

${ }^{37}$ Op. cit. TIRADO (2016), 4.

${ }^{38}$ Op. cit. SERRA PALAO (2019) 7; Op. cit. SALAZAR (2019) 69.

39 Op. cit. FRANCIONE y CHARLTON (2015) 32.

${ }^{40}$ De acuerdo a la Real Academia Española, el especismo se define como: “1. Discriminación de los animales por considerarlos especies inferiores; 2. Creencia según la cual el ser humano es superior al resto de los animales, y por ello puede utilizarlos en beneficio propio".

${ }^{41}$ Op. cit. COTELO (2013) 116.

${ }^{42}$ Op. cit. RÚA SERNA (2017) 113.
} 
A la luz de la capacidad de sintiencia que tienen los animales no humanos, y dadas las deficiencias asociadas a su actual consideración jurídica, ha surgido el debate sobre si su estatus de propiedad debe ser abolido $^{43}$. A continuación, se revisan de manera general los estatutos jurídicos propuestos en la literatura y en algunas legislaciones.

\subsubsection{Cosas, objetos, propiedad}

La consideración jurídica de los animales no humanos en tanto cosas es una herencia del Derecho Romano $^{44}$. Desde un punto de vista jurídico, una cosa tiene individualidad propia, es susceptible de apropiación, y es extraña al sujeto de derechos ${ }^{45}$. Las implicancias que tiene la atribución del estatus jurídico de cosa para los demás animales es que son susceptibles de ser objetos de propiedad, carecen de protección legal robusta, no tienen personalidad jurídica ni derechos legales y, por tanto, hay una consideración limitada a sus intereses, lo que permite su utilización para fines humanos y la ausencia de acciones jurídicas a su favor ${ }^{46}$. En tal sentido, los demás animales están sometidos al interés patrimonial o económico de los seres humanos, y las distintas situaciones en que pueden encontrarse, no las asume el Derecho en consideración a ellos, sino en atención al rendimiento o utilidad de los segundos. De ahí que no se considera a los animales no humanos en sí mismos, como realidad o valor natural ${ }^{47}$.

\subsubsection{Cosas especialmente protegidas, objetos de protección}

Doctrinariamente se ha planteado que, a propósito de la creciente preocupación por la conservación del medioambiente, se ha generado conciencia sobre la necesidad de preservar la vida animal y la biodiversidad, y que a nivel legal ello se concretó en un conjunto de leyes de protección, conservación y cuidado de los demás animales que, sin perder su naturaleza de cosas, han devenido en cosas especialmente protegidas ${ }^{48}$. Tal sería el caso de Chile, en que la facultad de disposición del dueño de un animal no humanos está limitada por la legislación, quien no puede disponer de él en forma totalmente libre, ya que legalmente no puede cometer actos de maltrato o crueldad en su contra y, en general, actos que le supongan un sufrimiento innecesario ${ }^{49}$.

Esta consideración se traduce en que el dominio, la posesión, e incluso la mera tenencia de un animal no humano, llevan consigo la obligación de cuidarlo y proporcionarle alimento y albergue adecuados, es decir, aquellos llevan ínsitos una carga u obligación real ${ }^{50}$. Sin embargo, parece claro que, si debe elegirse entre el respeto de los derechos fundamentales de las personas y la preservación de una cosa, por muy valiosa que ésta sea, ha de prevalecer lo primero ${ }^{51}$. En otras palabras, que el Derecho establezca determinadas obligaciones de los seres humanos en relación con los demás animales, no se colige que sean titulares de derechos ${ }^{52}$.

\subsubsection{Seres sensibles, seres sintientes}

En 2009, con la entrada en vigencia del Tratado de Funcionamiento de la Unión Europea (TFUE), los demás animales dejaron de ser cosas y pasaron a considerarse como seres sintientes ${ }^{53}$ a nivel constitucional en el Derecho europeo ${ }^{54}$. Esto no quiere decir que los animales no humanos hayan dejado de ser susceptibles de tráfico jurídico, sino que ese tráfico tiene ahora por objeto seres sintientes y no cosas ${ }^{55}$.

Algunos países en los que se ha optado por atribuir el estatus jurídico de ser sintiente o sensible a los

\footnotetext{
${ }^{43}$ Op. cit. FRANCIONE y GARNER (2010); Op. cit. FRANCIONE y CHARLTON (2015).

${ }^{44}$ Op. cit. GIMÉNEZ-CANDELA (2015) 12; Op. cit. WISE (2018) 13.

${ }^{45}$ CONTRERAS LÓPEZ, C., Régimen jurídico de los animales en Chile, Colombia y Argentina (Valencia 2016), 28.

${ }^{46}$ Op. cit. HORTA (2019) 41.

47 GONZÁLEZ MORÁN, L., El derecho frente a los animales, en Los derechos de los animales (Madrid 2002), 107.

${ }^{48}$ FIGUEROA YÁÑEZ, G., Los animales: ¿en trayecto desde el estado de cosa hasta el estado de persona?, en Estudios de Derecho Civil II (Santiago 2006) 73-74.

${ }^{49}$ BRAVO SILVA, D., Una relectura al estatuto jurídico de los animales en el Derecho chileno a partir de la vigencia de la Ley 20.380 , en Aproximaciones filosóficas y jurídicas al Derecho Animal (Santiago 2016) 116.

${ }^{50}$ Ibíd. 116.

${ }^{51}$ Op. cit. CORRAL TALCIANI (2018) 265.

${ }^{52}$ SQUELLA NARDUCCI, H. Introducción al Derecho (Santiago 2014) 173.

${ }^{53} \mathrm{Si}$ bien la versión en español del artículo 13 del cuerpo normativo señala "seres sensibles", la doctrina ha establecido que se trata de una cuestión de traducción del texto original que alude a "sentient beings". Para mayor detalle ver ALONSO (2015).

${ }^{54}$ ALONSO, E., El artículo 13 del Tratado de Funcionamiento de la Unión Europea: Los animales como seres "sensibles [sentientes]" a la luz de la jurisprudencia del Tribunal de Justicia de la Unión Europea, en Animales y Derecho (Valencia 2015), 18-19; LÓPEZ DE LA OSA ESCRIBANO, P., El Derecho del Bienestar Animal en Europa y Estados Unidos (Navarra 2012), 26-27.

${ }^{55}$ Op. cit. ALONSO (2015) 42.
} 
demás animales son Francia y Colombia. En el caso del primero, en 2015 se introdujo una modificación al Código Civil por la que pasaron a considerarse como "seres vivos dotados de sensibilidad". Sin embargo, se ha dicho que la nueva redacción parece tener un alcance simbólico, pues se les sigue aplicando el régimen jurídico de propiedad ${ }^{56}$. En tanto, el caso de Colombia es relevante pues fue el primer país de Latinoamérica en reconocer a los demás animales como seres sintientes de manera expresa en su Código Civil ${ }^{57}$.

\subsubsection{Sujetos de derechos, personas no humanas}

Desde el enfoque abolicionista, se afirma que los animales no humanos deben ser reconocidos como sujetos de derechos. Así, tendrían el derecho fundamental a no ser tratados como propiedad e implicaría la abolición de toda forma de explotación hacia ellos ${ }^{58}$. De acuerdo a FRANCIONE, ello supondría la existencia de un derecho "pre-legal" que debería ser reconocido legalmente, en la medida que los humanos comencemos a tomar en serio los intereses de los demás animales ${ }^{59}$.

Esta fórmula es la que, podríamos decir, se adoptó en 2014 por vía jurisprudencial en Argentina, a propósito del caso de la orangután Sandra ${ }^{60}$. En tal oportunidad, la II Sala de la Cámara Federal de Casación Penal declaró que "a partir de una interpretación jurídica dinámica y no estática, menester es reconocerle al animal el carácter de sujeto de derechos, pues los sujetos no humanos (animales) son titulares de derechos" (Considerando $2^{\circ}$ ). Situación similar ocurrió en 2015, también en Argentina, a propósito de la perra Poli ${ }^{61}$ y la chimpancé Cecilia ${ }^{62}$. Respecto de esta última, el tribunal afirmó que estos animales "poseen un catálogo de derechos fundamentales que debe ser objeto de estudio y enumeración por los órganos estatales que correspondan" y que "no se trata aquí de otorgarles los derechos que poseen los seres humanos, sino aceptar y entender de una buena vez que estos entes son seres vivos sintientes, que son sujetos de derechos y que les asiste, entre otros, el derecho fundamental a nacer, a vivir, a crecer, y morir en el medio que les es propio según su especie" (Considerando $\left.4^{\circ} \mathrm{c}\right)$.

\subsubsection{Ciudadanos, cuasi-ciudadanos, soberanos}

Además del nutrido debate sobre los derechos de los demás animales, en los últimos años se ha venido desarrollando el denominado "giro político", fundamentalmente gracias a la obra Zoopolis de DONALDSON \& KYMLICKA ${ }^{63}$. Con ello, la cuestión animal se ha extendido más allá de las discusiones sobre su bienestar, consideración, o derechos morales; alcanzando a su estatus político ${ }^{64}$. Los autores explican que las recientes luchas ciudadanas ofrecen una concepción de la ciudadanía fundada no en la posesión de capacidades como la razón, sino en los derechos de pertenencia y participación en una sociedad de iguales. Comprendida de esta manera, la ciudadanía sería una forma de reconocer a quienes en cuyo nombre gobierna el Estado y cuyo bien subjetivo debe ser considerado en la determinación del interés público ${ }^{65}$.

Bajo esta mirada, sería posible atender a las distintas formas en que los demás animales se relacionan con las instituciones políticas y las prácticas de soberanía del Estado, territorio, colonización, migración y pertenencia $^{66}$. De esta manera, DONALDSON \& KYMLICKA diferencian tres grupos de animales: domésticos, salvajes y liminales, no en función de la especie, sino las relaciones "políticas" que mantienen con los humanos. Los domésticos serían aquellos que forman parte de nuestra comunidad política en calidad de co-ciudadanos. Los salvajes no tendrían interés en formar parte de nuestra comunidad, pero indiscutiblemente nuestras acciones sobre el ecosistema les afectan, por lo que habrá que respetar su ámbito

\footnotetext{
${ }^{56}$ LELANCHON, L., La reforma del estatuto jurídico civil de los animales en el Derecho francés, en dA.Derecho Animal (Forum of Animal Law Studies) 9/3 (2018), 77. https://doi.org/10.5565/rev/da.344

${ }^{57}$ Op. cit. CONTRERAS LÓPEZ (2016) 278.

${ }^{58}$ Op. cit. FRANCIONE y CHARLTON (2015) 32.

${ }^{59}$ Op. cit. FRANCIONE (2004) 49-50.

${ }^{60}$ CÁMARA FEDERAL DE CASACIÓN PENAL (SEGUNDA SALA). 18 de diciembre de 2014. Causa N CCC 688312014 CFC1

"Orangutana Sandra s/ recurso de casación s/ habeas corpus".

${ }^{61}$ PRIMER JUZGADO CORRECCIONAL DE LA TERCERA CIRCUNSCRIPCIÓN JUDICIAL. 20 de abril de 2015. Sentencia N 1927, autos No 36.598 caratulados "F. C/ S.R.M.R. P/ maltrato y crueldad animal".

${ }^{62}$ TERCER JUZGADO DE GARANTÍAS DE MENDOZA. 03 de noviembre de 2016. Expediente P-72254/15. "Asociación de funcionarios y abogados por los derechos de los animales y otros contra GCBA sobre amparo"

${ }^{63}$ DONALDSON, S. y KYMLICKA, W., Zoopolis: A Political Theory of Animal Rights (New York 2011).

${ }^{64}$ LOEWE HENNY, D.H., Integración de los animales no humanos en la comunidad política: zoopolis, en Revista Chilena de Derecho Animal, 1 (2020), 44.

${ }^{65}$ DONALDSON, S. y KYMLICKA, W., Rethinking Membership and Participation in an Inclusive Democracy: Cognitive Disability, Children, Animals, en Disability and Political Theory (Cambridge 2016), 234-235. http://doi.org/10.1017/9781316694053.009

${ }^{66}$ DONALDSON, S. y KYMLICKA, W., Zoópolis, una revolución animalista (Madrid 2018) 441.
} 
de "soberanía". Finalmente, los liminales, aquellos que viven en nuestras ciudades pero no como animales domésticos, serían cuasi-ciudadanos, pues se encontrarían en una situación fronteriza al convivir con nosotros, aunque desinteresados en formar parte de la sociedad ${ }^{67}$. Lo anterior implica reconocer a los demás animales no sólo como sujetos individuales cuyos derechos básicos han de respetarse, sino como miembros de comunidades -tanto las nuestras como las suyas- entrelazadas en relaciones de interdependencia, mutualidad y responsabilidad. Esto daría lugar a "los cimientos de una futura zoópolis" "68.

\subsection{Brechas entre los estatus jurídicos atribuidos a los animales no humanos y las percepciones de la comunidad}

Para SHYAM, la estrecha relación entre Derecho y sociedad acarrea la necesidad de examinar si leyes centenarias continúan reflejando valoraciones y opiniones contemporáneas. Esto es especialmente útil cuando un aspecto del Derecho comienza a sentirse contra intuitivo, como ocurre con la situación jurídica de los animales no humanos. En este contexto -indica-, los estudios empíricos pueden ayudar a descubrir si la categorización de los demás animales como propiedad es consistente con las actitudes de la comunidad ${ }^{69}$.

Actualmente, es difícil describir con precisión las actitudes, valoraciones o percepciones de la comunidad acerca del estatus jurídico atribuido a los animales no humanos, pues los datos al respecto son escasos $^{70}$. De esta manera, sin evidencia empírica, sólo es posible especular sobre si alguno de los estatus jurídicos alternativos para algunos o todos los demás animales encontrarán aceptación social. De hecho, los argumentos a favor de la abolición del estatus de propiedad atribuido a estos individuos, a menudo se encuentran con pesimismo, pero ello parece estar más basado en la intuición que en la evidencia empírica ${ }^{71}$.

En los noventa, en una universidad estadounidense, VIGORITO aplicó una encuesta sobre actitudes hacia los derechos de los animales no humanos, consistente en 46 afirmaciones sobre diversos temas relacionados con la temática. Los resultados arrojaron que los estudiantes de los primeros años de Psicología tenían una actitud más negativa hacia la investigación en animales que los de los últimos años; asimismo, mostraron una actitud más positiva hacia el medio ambiente y hacia los problemas de los derechos de los demás animales que no se involucran en investigaciones ${ }^{72}$.

Según los resultados de una encuesta sobre actitudes hacia el bienestar y los derechos de los demás animales, aplicada a 3.433 estudiantes en universidades de 11 países europeos y asiáticos, fue posible concluir que la nacionalidad tuvo una gran influencia en las actitudes de los estudiantes hacia el bienestar y los derechos de estos individuos. Por ejemplo, los participantes de países europeos mostraron mayor preocupación por el bienestar de los demás animales, en comparación a los pertenecientes a países asiáticos. Las diferencias entre nacionalidades parecen explicarse, en parte, por las diferencias en la situación económica de los encuestados y, en parte, por el alcance de la legislación sobre el uso de animales no humanos en el país en cuestión ${ }^{73}$.

Una investigación de MOORE, efectuada en 2015, muestra que la gran mayoría de los estadounidenses -un 74\%- cree que los demás animales tienen ciertos derechos; sólo el 16\% estima que no tienen derechos, mientras que el $10 \%$ no está seguro ${ }^{74}$. En tanto, de acuerdo a un estudio de RIFFKIN, realizado también en 2015, casi un tercio de los estadounidenses -32\%-, cree que los demás animales deberían tener los mismos derechos que las personas, mientras que el $62 \%$ dice que merecen cierta protección, pero que aún pueden usarse en beneficio de los humanos. Esta sólida visión de los derechos de los animales no humanos fue superior a la mostrada en 2008, cuando el $25 \%$ pensaba que los derechos de los demás animales deberían estar a la par con los humanos ${ }^{75}$.

Un estudio de SHYAM, publicado en 2018, da cuenta de la aplicación de una encuesta a 287 personas en Victoria, Australia. El 58\% respondió que desconocía el estatus de propiedad de los animales no humanos.

\footnotetext{
${ }^{67}$ REY PÉREZ, J. L., El enfoque político de los derechos de los animales desde la teoría de los derechos, en Revista Iberoamericana de Bioética, 4 (2017), 9. https://doi.org/10.14422/rib.i04.y2017.002

${ }^{68}$ Op. cit. DONALDSON y KYMLICKA (2018) 446-448.

${ }^{69}$ Op. cit. SHYAM (2019) 77.

${ }^{70}$ Op. cit. SHYAM (2019) 76.

${ }^{71}$ Op. cit. SHYAM (2019) 73.

72 VIGORITO, M., An animal rights attitude survey of undergraduate psychology students, en Psychological Reports 79 (1996), 131. https://doi.org/10.2466/pr0.1996.79.1.131

${ }^{73}$ PHILLIPS, C. J. C., IZMIRLI, S., ALDAVOOD, S. J., ALONSO, M., CHOE, B. I., HANLON, A., HANDZISKA, A., ILLMAN, G., KEELING, J., KENNEDY, M, LEE, G. H., LUND, V., MEJDELL, C., PELAGIC, V. R. Y REHN, T., Students' attitudes to animal welfare and rights in Europe and Asia, en Animal Welfare-The UFAW Journal, 21/1 (2012), 95-97.

74 MOORE, P, Majority Endorse Animal Rights, en YouGov (2015). https://today.yougov.com/topics/lifestyle/articlesreports/2015/04/29/majority-endorse-animal-rights

${ }_{75}$ RIFFKIN, R., In US, more say animals should have same rights as people, en Gallup Social Issues, 18 (2015). https://news.gallup.com/poll/183275/say-animals-rights-people.aspx
} 
Solo una cuarta parte de los encuestados -26\%- estuvo de acuerdo en que los animales deberían clasificarse como propiedad. Ante la pregunta “¿Qué crees que influencia tu percepción sobre los animales?”, el factor más influyente fue las experiencias personales con animales -más del 80\%-, mientras que el segundo factor estaría dado por la educación -con cerca del 45\%-. El estudio también mostró que si bien los animales no humanos con los que convivimos se percibían en gran medida como "miembros de la familia" o "amigos", los animales no humanos considerados "de granja" eran más propensos a ser vistos como "seres vivos diferentes a los humanos"76.

SHYAM considera que estudios como los señalados pueden ser importantes para dar forma al Derecho Animal. Indica que tales antecedentes pueden proporcionar una indicación más justa de si la concepción de los demás animales como propiedad es consistente con lo que piensa la sociedad, o si un estatus jurídico alternativo podría reflejar mejor las actitudes de la comunidad. En tal sentido, precisa que se vuelve valioso para los académicos estudiar empíricamente las actitudes de la comunidad en este ámbito. Incluso, considera que dentro del área emergente del Derecho Animal, los datos pueden ayudar a validar o verificar los argumentos de abolicionistas y bienestaristas ${ }^{77}$. En cualquier caso, la autora aclara que no es su intención sugerir que el estatus jurídico de los animales no humanos debe determinarse sólo por las actitudes de la comunidad, pues ellas no siempre están alineadas con los principios morales. Además, reconoce que los datos empíricos pueden no siempre proporcionar una descripción precisa de las actitudes de la comunidad. Por ejemplo -indica-, a menudo, los encuestados no tienen una opinión sobre las preguntas que se les hacen en una encuesta, especialmente cuando se relacionan con problemas complejos. Así, depender solo de datos empíricos puede ser imprudente, de ahí que el valor de estos trabajos está en nutrir el debate ${ }^{78}$.

\section{Método}

\subsection{Diseño}

Para dar respuesta al objetivo de diseñar y validar una escala acerca del estatus jurídico atribuido a los animales no humanos, que permita develar las percepciones de la comunidad en relación a este asunto, el estudio persigue una metodología cuantitativa no experimental, de tipo exploratoria-descriptiva y con una recolección de datos de corte transversal ${ }^{79}$.

\subsection{Hipótesis}

Considerando las bases teóricas de este estudio se desprenden las siguientes hipótesis exploratorias:

- $\mathrm{H}_{1} \mathrm{E}$ : Se espera que la escala de percepciones acerca del estatus jurídico atribuido a los animales no humanos en la comunidad obtenga índices de fiabilidad y consistencia interna adecuados.

- $\mathrm{H}_{2} \mathrm{E}$ : Se espera que la escala sobre percepciones acerca del estatus jurídico atribuido a los animales no humanos responda a una estructura de tres variables: percepciones ético-jurídicas acerca de los animales no humanos en general; percepciones acerca de los derechos de los animales no humanos según destino atribuido; y aceptación de la satisfacción de necesidades humanas según destino distribuido a animales no humanos.

\subsection{Variables}

Las variables a analizar en esta investigación serán incluidas en el instrumento elaborado ad hoc, el cual pretende evaluar las percepciones de la comunidad sobre el estatus jurídico atribuido a los animales no humanos. Las variables están agrupadas en las categorías y criterios señalados en la Tabla 1.

\footnotetext{
${ }^{76}$ SHYAM, G., Is the classification of animals as property consistent with modern community attitudes?, en University of New South Wales Law Journal 41/4 (2018), 1430-1442.

${ }^{77}$ Op. cit. SHYAM (2018) 1426.

${ }^{78}$ Op. cit. SHYAM (2019) 68-69.

${ }^{79}$ HERNÁNDEZ, R., FERNÁNDEZ, C. y BAPTISTA, M., Metodología de la Investigación (México 2010).
} 
Tabla 1: Variables de la investigación

\begin{tabular}{|c|c|}
\hline Categoría & Criterio a evaluar \\
\hline $\begin{array}{l}\text { Variables } \\
\text { sociodemográficas }\end{array}$ & $\begin{array}{l}\text { Sexo, edad, país, nivel de formación, área de estudios y estilo de } \\
\text { alimentación }^{80} \text {. }\end{array}$ \\
\hline $\begin{array}{l}\text { Variables asociadas a las } \\
\text { percepciones que tiene la } \\
\text { comunidad sobre el } \\
\text { estatus jurídico atribuido a } \\
\text { los animales no humanos }\end{array}$ & $\begin{array}{l}\text { 1. Percepciones ético-jurídicas de los animales no humanos en } \\
\text { general: grado de acuerdo o desacuerdo acerca del actual estatus } \\
\text { ético-jurídico atribuido a los animales no humanos. } \\
\text { 2. Percepciones acerca de los derechos de los animales no } \\
\text { humanos según destino atribuido: grado de acuerdo o desacuerdo } \\
\text { acerca de los derechos de los animales no humanos según su destino } \\
\text { atribuido. } \\
\text { 3. Aceptación de la satisfacción de necesidades humanas según } \\
\text { destino distribuido a animales no humanos: grado de acuerdo o } \\
\text { desacuerdo acerca de la aceptación de la satisfacción de necesidades } \\
\text { humanas, según los distintos destinos atribuidos a animales no } \\
\text { humanos. }\end{array}$ \\
\hline
\end{tabular}

Fuente: Elaboración propia.

\subsection{Muestra}

La muestra no probabilística -donde los sujetos no son seleccionados al azar- y por conveniencia -que facilita el acceso a una muestra amplia- está compuesta por 639 sujetos, 451 mujeres (70,7\%), 178 hombres $(27,9 \%)$ y 9 otro $(1,4 \%)$. Sus edades fluctúan entre los $18(7,3 \%)$ y los $70(0,6 \%)$ años $(\mathrm{DT}=11,8 ; \mathrm{M}=31)$. Los/as participantes declaran como origen: Chile $(69,3 \%)$, Argentina (16,3\%) y Colombia $(5,3 \%)$. El máximo de estudios alcanzados es la educación secundaria (42,9\%), seguida por la Licenciatura o Título profesional $(33,4 \%)$ y el Master $(14,6 \%)$. El área de formación profesional preponderante son las Ciencias Sociales (76,9\%), las Ciencias Médicas y de la Salud (10,5\%) y las Humanidades (5,7\%). Asimismo, un 48,6\% de los/as participantes declara tener un estilo de alimentación omnívoro. Como criterios de selección de la muestra se ha considerado la participación de: a) mayores de edad; b) con o sin estudios universitarios y c) con o sin estudios en Derecho Animal.

Tabla 2: Características de la muestra

\begin{tabular}{lll}
\hline Variables & & $\%$ \\
\hline \multirow{3}{*}{ Sexo } & Mujer & 70,7 \\
& Hombre & 27,9 \\
& Otro & 1,4 \\
\hline \multirow{3}{*}{ Edad } & $18-35$ & 70,3 \\
& $36-53$ & 29,1 \\
& $54-70$ & 0,6 \\
\hline \multirow{3}{*}{ Origen } & Chile & 69,3 \\
& Argentina & 16,3 \\
& Colombia & 5,3 \\
& Otro & 9,1 \\
\hline \multirow{2}{*}{ Estudios } & Educación Secundaria & 42,9 \\
& Licenciatura & 33,4
\end{tabular}

\footnotetext{
${ }^{80}$ En lo relativo a los estilos de alimentación se utilizó la clasificación propuesta por: TAI LE, L. y SABATÉ, J., Beyond meatl ess, the health effects of vegan diets: findings from adventist cohorts, en Nutrients 6 (2014), 2131-2147. https://doi.org/10.3390/nu6062131. En este sentido, se considera como "omnívoro" o "no vegetariano" a quienes consumen carnes rojas, aves, pescado, lácteos y huevos más de una vez a la semana; "semi-vegetariano" a quienes consumen carnes rojas, aves y pescado menos de una vez a la semana y más de una vez al mes; "pescetariano" a quienes consumen pescado, lácteos y huevos, pero no carnes rojas ni aves; "ovo-lacto-vegetariano" a quienes consumen huevos, lácteos o ambos, pero no carnes rojas, pescado ni aves; y "vegano" a quienes no consumen carnes rojas, pescado, aves, lácteos y huevos.

66 Derecho Animal. Forum of Animal Law Studies, vol. 12/3
} 


\begin{tabular}{|c|c|c|}
\hline & $\begin{array}{l}\text { Máster / Magíster / Maestría } \\
\text { Otro }\end{array}$ & $\begin{array}{l}14,6 \\
9,1\end{array}$ \\
\hline \multirow{4}{*}{$\begin{array}{l}\text { Área } \\
\text { formación }\end{array}$} & Ciencias Sociales & 76,9 \\
\hline & $\begin{array}{l}\text { Ciencias Médicas y de la } \\
\text { Salud }\end{array}$ & 10,5 \\
\hline & Humanidades & 5,7 \\
\hline & Otra & 6,9 \\
\hline \multirow{4}{*}{$\begin{array}{l}\text { Estilo de } \\
\text { alimentación }\end{array}$} & Omnívoro & 48,6 \\
\hline & Semi-vegetariano & 21,2 \\
\hline & Vegano & 12,5 \\
\hline & Otro & 17,7 \\
\hline
\end{tabular}

Fuente: elaboración propia

En complemento a las características de la muestra, es preciso señalar que, en opinión de los/as encuestados/as, las experiencias personales, la crianza familiar y la educación constituyen los factores que influyen en su percepción y valoración de los animales no humanos. También, un 58,3\% declaran saber cómo son considerados, tratados o regulados los animales no humanos en la legislación de su país, y un 73,9\% señala que son cosas, objetos o propiedad.

Para la construcción del instrumento se siguieron las siguientes etapas:

1. Determinación de las variables objeto de medición: esta fase contempló la especificación de cada una de las variables que conforman la escala. Para ello se llevó a cabo una amplia revisión de la literatura. Esta primera parte del estudio permitió determinar los 4 apartados del instrumento: a) Variables sociodemográficas de los participantes; b) Percepciones ético-jurídicas acerca de los animales no humanos en general; c) Percepciones acerca de los derechos de los animales no humanos según su destino atribuido; y d) Aceptación de la satisfacción de necesidades humanas según destino distribuido a animales no humanos. Es importante señalar que los destinos atribuidos a los animales no humanos (p.e., convivencia, alimentación, vestimenta, espectáculo, trabajo, experimentación y testeo, silvestres y salvajes) constituyen los ámbitos frecuentemente señalados por la literatura ${ }^{81}$. De esta etapa, surgieron un banco inicial de 40 reactivos, basados también en la revisión de la literatura ${ }^{82}$. Se determinó el formato de cada variable, de sus reactivos, y la graduación ante cada respuesta.

2. Juicio de expertos: para la validación de contenido se contó con la participación de 14 expertos, todos profesionales con los grados de magíster y/o doctor, dedicados a la docencia en instituciones de educación superior, en las áreas del Derecho, Ética, Metodología de la Investigación y Educación. Dichos expertos valoraron la pertinencia de los 40 ítems para medir el constructo con tres posibilidades: 1) innecesario, 2) útil pero prescindible y 3) esencial. Una vez obtenida la opinión de los expertos, se extrajo el Índice de Validez de Contenido (IVC) de LAWSHE ${ }^{83}$. Los resultados arrojaron una escala general de 26 ítems, con un índice de .74, valor adecuado y en el rango de los expertos participantes en este proceso ${ }^{84}$. De esta manera, la validación de contenido revela que el contenido que se pretende evaluar es preciso y suficiente.

3. Composición de la escala sobre estatus jurídico de los animales: la composición de la escala autoconstruida consta de 26 ítems, graduados en una escala Likert donde 1 es "totalmente en desacuerdo" y 7 "totalmente de acuerdo". Los ítems se distribuyeron en tres variables: a) "Percepciones ético-jurídicas acerca de los animales no humanos en general" con 8 reactivos (p.e., Los animales deben tener derechos en sentido jurídico); b) "Percepciones acerca de los derechos de los animales no humanos según su destino atribuido" con 9 reactivos (p.e., Los derechos de los

\footnotetext{
${ }^{81}$ Op. cit. SINGER (1975); op. cit. FRANCIONE (1995); op. cit. DONALDSON y KYMLICKA (2011); op. cit. HORTA (2017); op. cit. SHYAM (2018); op. cit. LEYTON DONOSO (2019), etc.

${ }^{82}$ En este sentido, por ejemplo, se tuvo en cuenta la recomendación formulada por SHYAM (2018), en orden a indagar en el conocimiento de los encuestados acerca del estatus jurídico atribuido a los animales no humanos (p. 1428). Del mismo modo, se consideró la posibilidad de detectar valoraciones diversas acerca del estatus jurídico atribuido a los demás animales, en función de los distintos tipos de relaciones que mantenemos con ellos -animales con los que convivimos, animales destinados a la alimentación, etc(SHYAM, 2019, p. 78).

${ }^{83}$ LAWSHE, C., A quantitative approach to content validity, in Personnel Psychology, 28/4 (1975).

${ }^{84}$ PEDROSA, I., SUÁREZ-ÁLVAREZ, J. Y GARCÍA-CUETO, E., Evidencias sobre la validez de contenido: Avances teóricos y métodos para su estimación, en Acción Psicológica, 10/2 (2013).
} 
animales destinados para experimentación biomédica deben tener el mismo valor o importancia jurídica que los derechos de los seres humanos); y c) "Aceptación de la satisfacción de necesidades humanas según destino distribuido a animales no humanos" con 9 reactivos (p.e., Los animales salvajes no deben ser usados para satisfacer necesidades de los seres humanos). Para efectos de validación de constructo, se llevó a cabo un análisis de fiabilidad con alfa de Cronbach y un análisis factorial exploratorio, a continuación, se detallan los análisis.

\subsection{Procedimiento para la recolección de los datos}

Los datos fueron recolectados mediante un cuestionario online utilizando la plataforma Google Forms, entre diciembre de 2020 y abril de 2021. En cuanto a los aspectos éticos, se siguieron los tres principios fundamentales de la ética de la investigación, estos son: a) respeto por las personas; b) beneficencia y, c) justicia. En cuanto al respeto por las personas, los/as participantes pudieron leer los objetivos de la investigación y aprobar o rechazar su participación a través de un consentimiento informado. Por su parte, en cuanto a la beneficencia, cabe señalar que el cuestionario no presentaba ningún tipo de daño físico, psicológico o social al contestarlo. Por último, en cuanto a la justicia, este cuestionario no consideraba ningún tipo de retribución o beneficio pecuniario, ni tampoco riesgo para los participantes.

\section{Análisis de los resultados}

El análisis de los datos fue llevado a cabo con SPSS (v. 22) para Windows y se utilizaron las siguientes técnicas estadísticas: 1) Análisis factorial exploratorio para cada una de las variables del cuestionario, donde se utilizó la extracción de componentes principales y rotación Varimax considerando la prueba de esfericidad de Bartlett, el índice KMO de Kaiser-Meyer-Olkin, las comunalidades y la varianza explicada; y 2) Coeficientes alfa de Cronbach para cada una de las variables. Más específicamente, el índice de Bartlett se consideró para determinar si existe relación significativa entre las variables analizadas, siendo adecuado cuando p $<0.05$ y el KMO cuando se aproxima a 1 la significación es elevada ${ }^{85}$. Para las comunalidades, entendidas como la proporción de varianza explicada por el conjunto de factores comunes resultantes, se respetó saturaciones $>.40^{86}$. La varianza explicada permite evidenciar el ajuste del modelo ${ }^{87}$. Finalmente, el alfa de Cronbach permite identificar la consistencia interna de la escala, que para Ciencias Sociales se sitúa en el punto de corte $.70^{88}$. A continuación, se presentan los resultados de los análisis para las tres variables del cuestionario.

\subsection{Análisis 1: Análisis Factorial Exploratorio para la variable Percepciones ético-jurídicas acerca de los animales no humanos en general}

Para realizar el análisis factorial, se evaluó la medida de adecuación muestral KMO -Kaiser, Meyer y Olkin- y la prueba de Bartlett. La primera prueba resultó positiva con un coeficiente de .958, considerado como un valor superior ${ }^{89}$. Por su parte, la Prueba de Bartlett confirma que las relaciones entre las variables son significativas $(\mathrm{p}<0.05)$.

Tabla 3: Índice de Bartlett

\begin{tabular}{lll}
\hline \multicolumn{2}{l}{$\begin{array}{l}\text { Medida Kaiser-Meyer-Olkin de adecuación de } \\
\text { muestreo }\end{array}$} & .893 \\
\hline \multirow{3}{*}{$\begin{array}{l}\text { Prueba de esfericidad } \\
\text { de Bartlett }\end{array}$} & Aprox. Chi-cuadrado & $\begin{array}{l}1132,56 \\
\end{array}$ \\
\cline { 2 - 3 } & $\mathrm{gl}$ & 0 \\
\cline { 2 - 3 } & Sig. & 28 \\
\hline
\end{tabular}

Como se puede apreciar en la Tabla 4, las comunalidades de los 8 reactivos que componen esta variable

\footnotetext{
${ }^{85}$ CEA, M. A., Análisis multivariable. Teoría y práctica en la investigación social (Madrid 2004).

${ }^{86}$ GARCÍA-CUETO, E y FIDALGO, A., Análisis de los ítems. En J. Muñiz, A. Fidalgo, E. García Cueto, R. Martínez y R. Moreno (Eds), Cuadernos de Estadística 30. Análisis de los ítems (Madrid 2005).

${ }^{87}$ FERRANDO, P. J. y ANGUIANO, C., El análisis factorial como técnica de investigación en psicología, en Papeles del Psicólogo, 31/1 (2010).

${ }^{88}$ NUNNALLY, J. C., y BERNSTEIN, I. H., Psychometric Theory (New York 1994).

${ }^{89}$ KAISER, H., An index of factorial simplicity, en Psychometrika, 39/1 (1974).

68 Derecho Animal. Forum of Animal Law Studies, vol. 12/3
} 
van en un rango de .146 a .745. Cabe señalar además que, si bien dos ítemes presentan una carga de saturación $>.40$, estos se mantuvieron en el modelo, porque los reactivos explican en su conjunto una varianza explicada de $54,53 \%$ y un $\alpha=.84$.

Tabla 4: Comunalidades

Método de extracción: Análisis de componentes principales

\begin{tabular}{lll}
\hline Ítem & Inicial & Extracción \\
\hline Ítem 1 & 1,000 &, 146 \\
Ítem 2 & 1,000 &, 322 \\
Ítem 3 & 1,000 &, 654 \\
Ítem 4 & 1,000 &, 710 \\
Ítem 5 & 1,000 &, 745 \\
Ítem 6 & 1,000 &, 640 \\
Ítem 7 & 1,000 &, 653 \\
Ítem 8 & 1,000 &, 491 \\
\hline
\end{tabular}

Tabla 5: Varianza Total Explicada

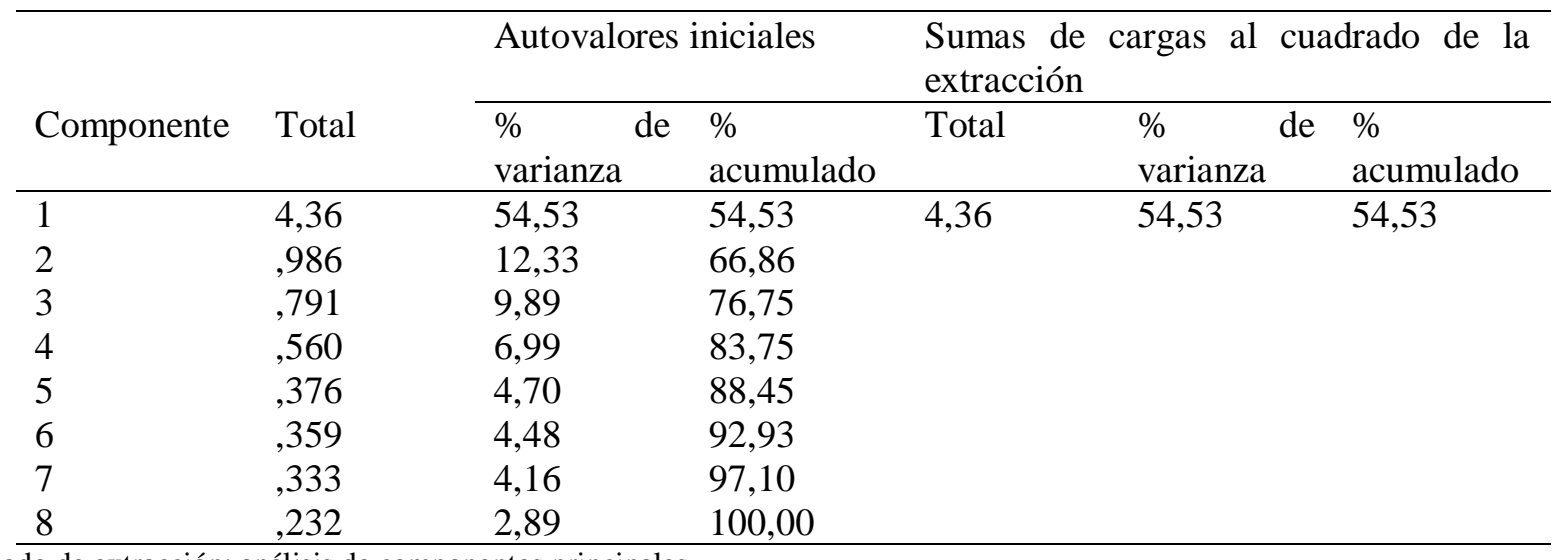

Método de extracción: análisis de componentes principales

Tabla 6: Alfa de Cronbach

\begin{tabular}{llll}
\hline $\begin{array}{l}\text { Alfa } \\
\text { Cronbach }\end{array}$ & de & $\begin{array}{l}\text { Alfa de Cronbach basada } \\
\text { en } \\
\text { estandarizados }\end{array}$ & $\begin{array}{l}\mathrm{N} \\
\text { elementostos }\end{array}$ \\
\hline .84 & .87 & 8 \\
\hline
\end{tabular}

\subsection{Análisis 2: Análisis Factorial Exploratorio de Percepciones acerca de los derechos de los animales no humanos según su destino atribuido}

La medida de adecuación muestral KMO -Kaiser, Meyer y Olkin- resultó positiva con un coeficiente de .958 y la Prueba de Bartlett confirma que las relaciones entre las variables son significativas $(\mathrm{p}<0.05)$, siendo viable realizar el análisis factorial.

Tabla 7: Prueba KMO y Bartlett

\begin{tabular}{lll}
\hline $\begin{array}{l}\text { Medida } \\
\text { muestreo }\end{array}$ & Kaiser-Meyer-Olkin de adecuación de & .958 \\
\hline \multirow{3}{*}{$\begin{array}{l}\text { Prueba de esfericidad de } \\
\text { Bartlett }\end{array}$} & Aprox. Chi-cuadrado & 7829,83 \\
& & 9 \\
\cline { 2 - 3 } & $\mathrm{gl}$ & 36 \\
\cline { 2 - 3 } & Sig. &, 000 \\
\hline
\end{tabular}

Por su parte, en la Tabla 8 se muestran las comunalidades de los 9 reactivos que componen esta variable. 
Cabe señalar que dichos reactivos revelaron discriminaciones en un rango de .710 a .912 , y por lo tanto $>.40^{90}$. Sumado a lo anterior, el análisis de componentes principales con rotación Varimax, para la variable "Percepciones acerca de los derechos de los animales no humanos según su destino atribuido" arrojó una varianza total explicada de 83,07\% (ver tabla 9).

Tabla 8: Comunalidades

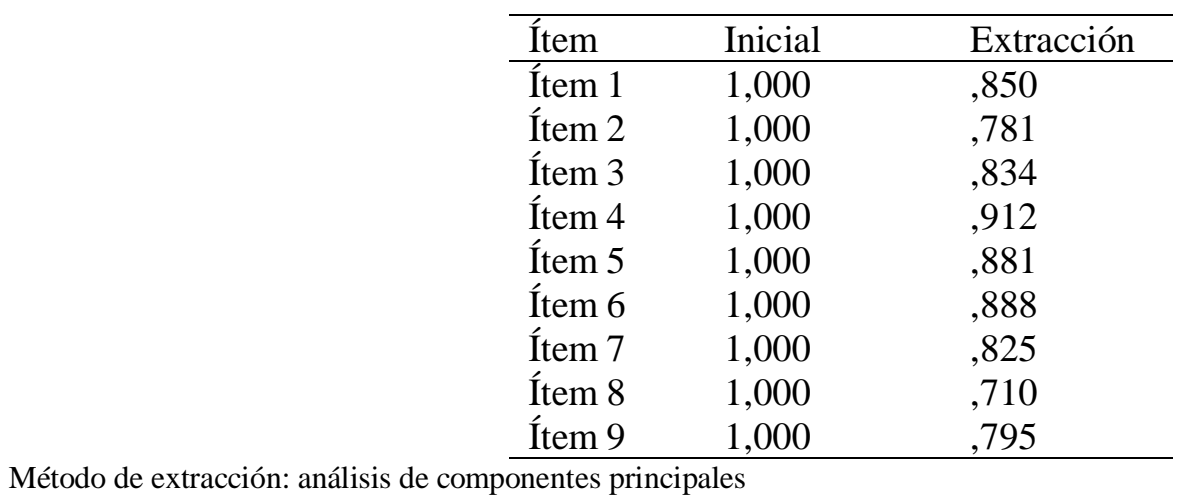

Tabla 9: Varianza Total Explicada

\begin{tabular}{|c|c|c|c|c|c|c|}
\hline \multirow[b]{2}{*}{ Componente } & \multirow[b]{2}{*}{ Total } & \multicolumn{2}{|c|}{ Autovalores iniciales } & \multicolumn{3}{|c|}{$\begin{array}{l}\text { Sumas de cargas al cuadrado de la } \\
\text { extracción }\end{array}$} \\
\hline & & $\begin{array}{l}\% \text { de } \\
\text { varianza }\end{array}$ & $\begin{array}{l}\% \\
\text { acumulado }\end{array}$ & Total & $\begin{array}{l}\% \text { de } \\
\text { varianza }\end{array}$ & $\begin{array}{l}\% \\
\text { acumulado }\end{array}$ \\
\hline 1 & 7,47 & 83,07 & 83,07 & 7,47 & 83,07 & 83,07 \\
\hline 2 &, 354 & 3,93 & 87,00 & & & \\
\hline 3 & ,266 & 2,96 & 89,96 & & & \\
\hline 4 & ,227 & 2,52 & 92,49 & & & \\
\hline 5 & ,216 & 2,39 & 94,88 & & & \\
\hline 6 &, 171 & 1,89 & 96,78 & & & \\
\hline 7 &, 129 & 1,43 & 98,21 & & & \\
\hline 8 & ,097 & 1,07 & 99,29 & & & \\
\hline 9 &, 064 &, 710 & 100,00 & & & \\
\hline
\end{tabular}

Método de extracción: análisis de componentes principales

En cuanto a la fiabilidad del cuestionario para los 9 reactivos, el índice $\alpha$ de Cronbach arrojó .97.

Tabla 10: Alfa de Cronbach

\begin{tabular}{lll}
\hline $\begin{array}{l}\text { Alfa de } \\
\text { Cronbach }\end{array}$ & $\begin{array}{l}\text { Alfa de Cronbach basada en } \\
\text { elementos estandarizados }\end{array}$ & $\begin{array}{l}\text { N de } \\
\text { elementos }\end{array}$ \\
\hline .97 & .97 & 9 \\
\hline
\end{tabular}

\subsection{Análisis 3: Análisis Factorial Exploratorio de Aceptación de la satisfacción de necesidades humanas según destino distribuido a animales no humanos}

En la misma línea de los análisis anteriores, la variable "Aceptación de la satisfacción de necesidades humanas según destino distribuido a animales no humanos" presentó índices favorables para realizar el análisis factorial, considerando el KMO -Kaiser, Meyer y Olkin- con un coeficiente de .915 y la Prueba de Bartlett con relaciones significativas entre las variables $(\mathrm{p}<0.05)$.

Tabla 11: Prueba KMO y Bartlett

Medida Kaiser-Meyer-Olkin de adecuación de ,915 muestreo

\footnotetext{
${ }^{90}$ Op. cit. GARCÍA-CUETO y FIDALGO (2005).

70 Derecho Animal. Forum of Animal Law Studies, vol. 12/3
} 


\begin{tabular}{lll}
\hline \multirow{2}{*}{$\begin{array}{l}\text { Prueba de esfericidad de } \\
\text { Bartlett }\end{array}$} & Aprox. Chi-cuadrado & 3053,49 \\
\cline { 2 - 3 } & & 3 \\
\cline { 2 - 3 } & gl & 36 \\
\cline { 2 - 3 } & Sig. &, 000 \\
\hline
\end{tabular}

Las comunalidades de los 9 reactivos que componen esta dimensión revelaron discriminaciones en un rango de .434 a .679 , y por lo tanto $>.40^{91}$. Asimismo, el análisis de componentes principales con rotación Varimax reveló para esta variable un 56,76\% de varianza total explicada de (ver tabla 12).

Tabla 12: Comunalidades

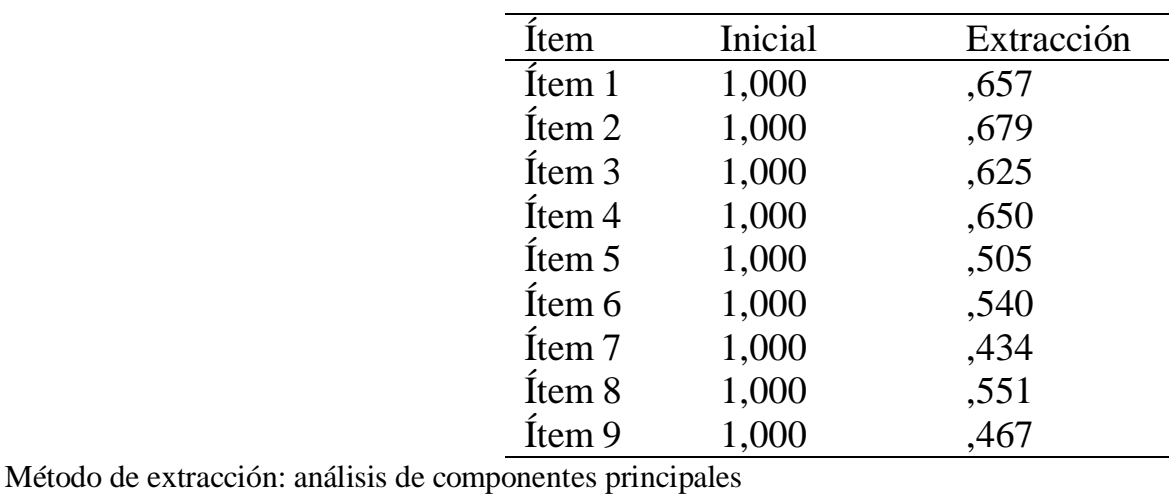

Tabla 13: Varianza Total Explicada

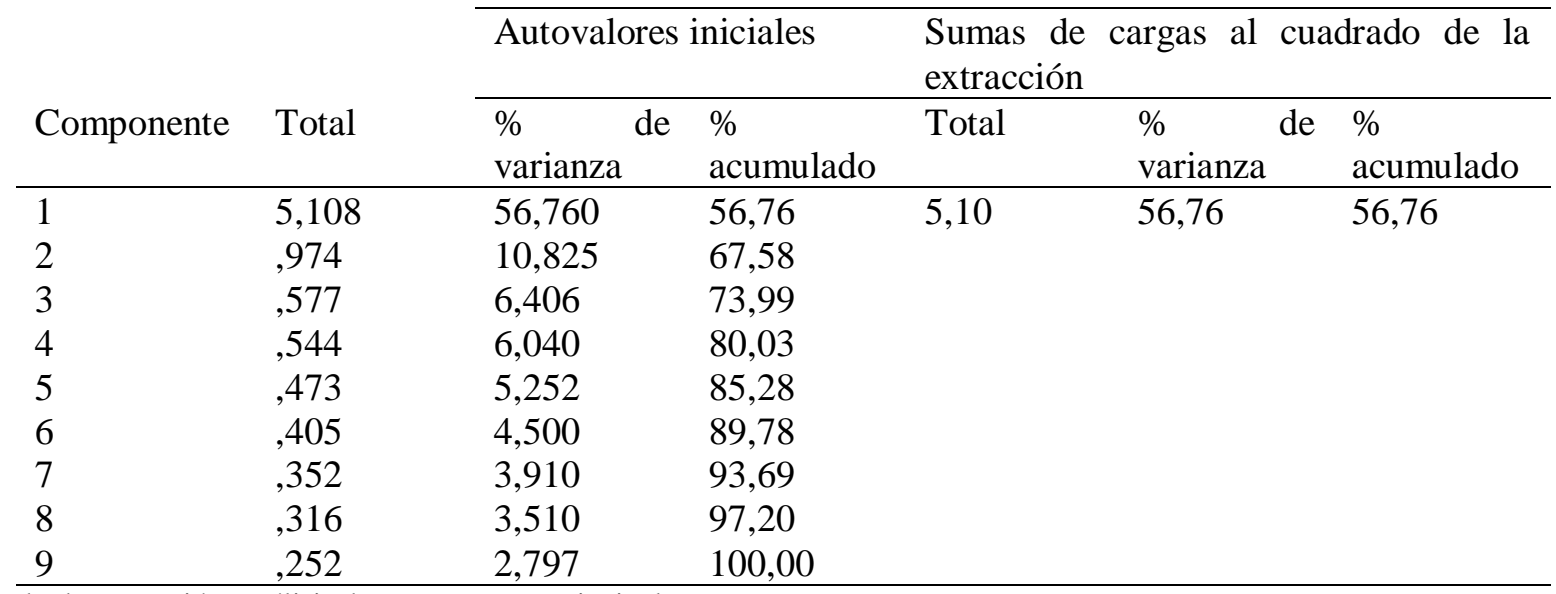

Método de extracción: análisis de componentes principales

Por último, la fiabilidad del cuestionario para los 9 reactivos, arrojó un índice $\alpha$ de Cronbach arrojó .90 .

Tabla 14: Alfa de Cronbach

\begin{tabular}{lll}
\hline $\begin{array}{l}\text { Alfa de } \\
\text { Cronbach }\end{array}$ & $\begin{array}{l}\text { Alfa de Cronbach basada } \\
\text { en } \\
\text { estandarizados }\end{array}$ & $\begin{array}{l}\mathrm{N} \text { de } \\
\text { elementos }\end{array}$ \\
\hline, 90 &, 90 & 9 \\
\hline
\end{tabular}

\section{Discusión}

Abordar las percepciones que una comunidad alberga en torno al estatus jurídico atribuido a los animales no humanos no sólo constituye un avance en el conocimiento teórico existente sobre la materia, sino que además ofrece una mirada métrica a un constructo que hoy es parte de la política pública en diversos Estados. Más específicamente, explorar y describir las variables asociadas a las percepciones ético-jurídicas de la comunidad hacia los animales no humanos en general, sus derechos, así como el grado de aceptación

${ }^{91}$ Op. cit. GARCÍA-CUETO y FIDALGO (2005). 
acerca de la satisfacción de necesidades humanas con ellos, abren el camino para que la toma de decisiones en diversos ámbitos pueda considerar también la evidencia empírica, reconociendo en todo caso la dificultad en la precisión que conlleva el estudio de las percepciones de una comunidad.

De acuerdo con los resultados obtenidos en este estudio, se puede indicar que las dos hipótesis planteadas han sido confirmadas. En primer lugar, desde la fiabilidad y la consistencia interna, las tres variables alcanzaron índices de fiabilidad y consistencia interna por sobre el punto de corte .70, para las Ciencias Sociales". Se destaca la variable asociada a "Percepciones acerca de los derechos de los animales no humanos según el destino atribuido" cuyo $\alpha$ de Cronbach arrojó .97, esto significa que dicha variable cuenta con muy buenas propiedades psicométricas y, por lo mismo, fiabilidad para evaluar el constructo. En segundo lugar, la hipótesis de la estructura factorial responde a las tres variables del estudio con varianza total explicada para "Percepciones ético-jurídicas acerca de los animales no humanos en general" de 53,4\%; "Percepciones acerca de los derechos de los animales no humanos según destino atribuido" de 83,07\%; y "Aceptación de la satisfacción de necesidades humanas según destino distribuido a animales no humanos" de $56,76 \%$. De esta manera, el análisis factorial exploratorio confirma la validez de la escala y la existencia de tres variables claramente diferenciadas. Cabe señalar que, pese a la escasa evidencia empírica para medir las percepciones ciudadanas acerca del estatus jurídico atribuido a los animales no humanos, estos resultados convergen con la propuesta de VIGORITO ${ }^{93}$, en el sentido que el constructo presenta variables separadas y, como consecuencia, no es unidimensional.

Por otro lado, se debe señalar que esta investigación evidencia puntos de encuentro con otros estudios como los de SHYAM $^{94}$ y MOORE ${ }^{95}$, que instan a seguir nutriendo la teoría y además a construir propuestas métricas -válidas y fiables- para abordar las diferencias en la medición del estatus jurídico atribuido a los animales no humanos. En efecto, si una comunidad desconoce el estatus jurídico que se le atribuye a los demás animales, es poco probable que evalúe la corrección ética o la idoneidad de dicho estatus. También es poco probable que una comunidad considere formas alternativas de categorizarlos jurídicamente si no saben, por ejemplo, que actualmente están clasificados como propiedad ${ }^{96}$. Por lo tanto, dirigir la discusión hacia estudios con trayectorias metodológicas que consideren el rigor científico, materializado en el juicio de expertos, la validación del constructo, y los resguardos éticos -propios de los estudios que consideran la participación de sujetos- no solo constituyen una necesidad, sino un deber para proyectar un modelo acerca del estatus jurídico atribuido a los animales no humanos.

Como indica SHYAM, se ha verificado que las leyes que reflejan los valores de la comunidad tienen más probabilidades de ser aceptadas y consideradas sustancialmente legítimas ${ }^{97}$. De ahí que las variables que dan forma a la escala diseñada ad hoc dan cabida al amplio espectro de animales no humanos con los que convivimos en diversos contextos, y dan espacio para que la comunidad pueda manifestar sus percepciones y, como consecuencia, comenzar a incidir en el debate que suscita el desarrollo del Derecho Animal. Por ejemplo, para los participantes del estudio de SHYAM, los animales salvajes eran los menos propensos a ser vistos como propiedad y, en su mayoría, eran percibidos como "importantes tesoros nacionales". En la misma línea, pero como dato complementario, dicho resultado es coincidente con el 43,4\% de los encuestados de este estudio, quienes consideran a los animales salvajes como sujetos de derecho y personas no humanas, mientras que un $40,1 \%$ seres sensibles/sintientes. Ambos hallazgos revelan que diferentes sentimientos están unidos a diferentes categorías de animales no humanos ${ }^{98}$. Más aún, estos resultados también ponen de relieve la incomodidad asociada con el estatus de propiedad atribuido a, al menos, algunos animales ${ }^{99}$. En definitiva, indagar en las percepciones modernas de la comunidad acerca de los animales no humanos puede agregar peso a los argumentos para cambiar el estatus jurídico que se les atribuye ${ }^{100}$.

Otro dato emanado del estudio de SHYAM, revela que una importante parte de los encuestados -58\%no estaban al tanto del estatus de propiedad atribuido a los animales no humanos, lo que puede ser explicado por el hecho de que no habían recibido educación en este ámbito ${ }^{101}$. Este hallazgo también constituye un punto de encuentro, puesto que el 58,3\% de los participantes de este estudio declara saber el estatus de propiedad atribuido a los animales no humanos, mientras que el resto no tiene conocimiento. Esto resalta, por una parte,

\footnotetext{
${ }^{92}$ Op. cit. NUNNALLY y BERNSTEIN (1994).

${ }^{93}$ Op. cit. VIGORITO (1996).

${ }^{94}$ Op. cit. SHYAM (2018).

95 Op. cit. MOORE (2015).

${ }^{96}$ Op. cit. SHYAM (2018) 1430; Op. cit. SHYAM (2019) 76-77.

${ }^{97}$ Op. cit. SHYAM (2018) 1425.

${ }^{98}$ Op. cit. SHYAM (2019) 77.

${ }^{99}$ Op. cit. SHYAM (2018) 1431.

100 Op. cit. SHYAM (2019) 79.

${ }^{101}$ Op. cit. SHYAM (2018) 1441-1442.
} 
la responsabilidad por informarse acerca de cuestiones jurídicas relevantes, pero por otra, la importancia de los programas formativos orientados a promover el respeto y cuidado de los animales no humanos. En este sentido, por ejemplo, refuerza el valor de los cursos de Derecho Animal, cada vez están más presentes en los programas de formación para abogados en instituciones de educación superior ${ }^{102}$, no así en otras disciplinas. Esto tiene una importancia clave, pues más allá de los avances normativos y jurisprudenciales que dan mayor protección a los animales no humanos, es necesario que exista un cambio cultural en este ámbito, y ello sólo se logrará a través de la educación ${ }^{103}$.

\section{Conclusiones}

Con base en lo expuesto, el estudio aporta con una escala que permite evaluar las percepciones de la comunidad acerca del estatus jurídico atribuido a los animales no humanos, cuestión que permitirá contribuir con evidencia empírica el debate sobre la materia. Esto, sin duda, nutre el desarrollo del Derecho Animal y colabora con la comunidad científica para futuros estudios en un área de incipiente exploración.

Las implicancias prácticas del estudio se concretan en: 1) contar con una escala original y novedosa para evaluar las percepciones de la comunidad con respecto al estatus jurídico atribuido a los animales no humanos; 2) contrastar lo establecido jurídicamente con aquello que percibe una sociedad a su respecto; 3 ) promover procesos de enseñanza-aprendizaje en Derecho Animal en los distintos niveles educativos; y 4) generar estudios de impacto para comprobar la influencia de los programas de formación relativos al cuidado y respeto por los demás animales en la comprensión y percepción acerca de los estatus jurídicos que se les atribuye.

Como fortalezas del estudio, es posible indicar la muestra de 639 sujetos con diversidad de origen, edad, estudios, entre otros, lo que permite contar con una escala cuyos análisis estadísticos y técnicas robustas confirman sus propiedades psicométricas. También, constituye un aporte desde Latinoamérica, para el establecimiento del diálogo entre el Derecho y las percepciones de la comunidad.

Las limitaciones del estudio están asociadas a una muestra no probabilística y por conveniencia, que impiden generalizar sus resultados, así como también el sesgo de los sujetos participantes que se identificaron como activistas por los derechos de los demás animales. También, considerando que se trata de un enfoque cuantitativo para evaluar las percepciones de la comunidad respecto al estatus jurídico atribuido a los animales no humanos, resulta necesario ampliar la mirada del fenómeno desde otras aproximaciones.

Para finalizar se sugiere que futuras investigaciones aborden la problemática desde una perspectiva cualitativa o mixta, asimismo, que amplíen y diversifiquen la muestra considerando una recolección de datos con corte longitudinal. En resumen, este estudio contribuye a la comprensión del estatus jurídico atribuido a los animales desde las percepciones de la comunidad en las variables de: a) "Percepciones ético-jurídicas acerca de los animales no humanos en general"; b) "Percepciones acerca de los derechos de los animales no humanos según su destino atribuido" y c) "Aceptación de la satisfacción de necesidades humanas según destino distribuido a animales no humanos". Finalmente, es preciso indicar que la tarea investigativa en este ámbito no concluye, sino que recién comienza, por lo que se convoca a seguir robusteciendo esta propuesta métrica y, más importante, a aplicar el instrumento para así revelar las percepciones que la comunidad tiene acerca del estatus jurídico atribuido a los animales no humanos.

\section{Bibliografía}

- ALONSO, E., El artículo 13 del Tratado de Funcionamiento de la Unión Europea: Los animales como seres "sensibles [sentientes]" a la luz de la jurisprudencia del Tribunal de Justicia de la Unión Europea, en Animales y Derecho (Valencia 2015).

- BEKOFF, M y MEANEY, C. A., Encyclopedia of animal rights and animal welfare (Connecticut 1998).

- BRAVO SILVA, D., Una relectura al estatuto jurídico de los animales en el Derecho chileno a partir de la vigencia de la Ley 20.380, en Aproximaciones filosóficas y jurídicas al Derecho Animal (Santiago 2016).

- CEA, M. A., Análisis multivariable. Teoría y práctica en la investigación social (Madrid 2004).

- CONTRERAS LÓPEZ, C., Régimen jurídico de los animales en Chile, Colombia y Argentina (Valencia 2016).

\footnotetext{
102 Véase GIMÉNEZ-CANDELA, M. y CERSOSIMO, R., La enseñanza del derecho animal (Valencia 2021).

${ }^{103}$ MONTES FRANCESCHINI, M., Derecho Animal en Chile (Santiago 2018), 113.
} 
- COMPASSION IN WORLD FARMING, Por qué el bienestar de los peces es importante: la evidencia de la sintiencia en peces (Madrid 2020).

- CORRAL TALCIANI, H., Curso de Derecho Civil: parte general (Santiago 2018).

- COTELO, S., Veganismo: de la teoría a la acción (Madrid 2013).

- DONALDSON, S. y KYMLICKA, W., Zoopolis: A Political Theory of Animal Rights (New York 2011).

- DONALDSON, S. y KYMLICKA, W., Rethinking Membership and Participation in an Inclusive Democracy: Cognitive Disability, Children, Animals, en Disability and Political Theory (Cambridge 2016). http://doi.org/10.1017/9781316694053.009

- DONALDSON, S. y KYMLICKA, W., Zoópolis, una revolución animalista (Madrid 2018).

- FERRANDO, P. J. y ANGUIANO, C., El análisis factorial como técnica de investigación en psicología, en Papeles del Psicólogo, 31/1 (2010).

- FIGUEROA YÁÑ̃Z, G., Los animales: ¿en trayecto desde el estado de cosa hasta el estado de persona?, en Estudios de Derecho Civil II (Santiago 2006).

- FRANCIONE, G., Animals, Property, and the Law (Philadelphia 1995).

- FRANCIONE, G. Animals-Property or Persons?, en Rutgers Law School (Newark) Faculty Papers, working paper 21 (2004).

- FRANCIONE, G. L. y CHARLTON, A., Animal rights: the abolitionist approach (Lexington 2015).

- FRANCIONE, G. L. y GARNER, R., Introduction en The animal rights debate: abolition or regulation? (New York 2010).

- GALlEGO SAADE, J., Sobre la posibilidad de un 'Derecho Animal', en Derecho Animal: teoría y práctica (Santiago 2018).

- GARCÍA-CUETO, E y FIDAlgO, A., Análisis de los ítems. En J. Muñiz, A. Fidalgo, E. García Cueto, R. Martínez y R. Moreno (Eds), Cuadernos de Estadística 30. Análisis de los ítems (Madrid 2005).

- GARNER, R., A Defense of a Broad Animal Protectionism, en The animal rights debate: abolition or regulation? (Nueva York 2010).

- GIMÉNEZ-CANDELA, T., Introducción, en Animales y Derecho (Valencia, 2015).

- GIMÉNEZ-CANDELA, M. y CERSOSIMO, R., La enseñanza del derecho animal (Valencia 2021).

- GONZÁLEZ MARINO, I., Animales no humanos como sujetos ante el Derecho y limitaciones al ejercicio de derechos fundamentales: algunos desafíos a propósito de la jurisprudencia reciente, en Discusiones y desafíos en torno al Derecho Animal (Santiago 2018).

- GONZÁLEZ MORÁN, L., El derecho frente a los animales, en Los derechos de los animales (Madrid 2002).

- HERNÁNDEZ, R., FERNÁNDEZ, C. y BAPTISTA, M., Metodología de la Investigación (México 2010).

- HORTA, O., Un paso adelante en defensa de los animales (Madrid 2017).

- HORTA, O., Ética y animales no humanos: conceptos básicos, en Manual de Derecho Animal (Buenos Aires 2019).

- JIMÉNEZ CHAMORRO, J. M., Biodiversidad y veterinaria, ante el animalismo: parte II, Animalismo y veterinaria, en Badajoz Veterinaria 12 (2018).

- KAISER, H., An index of factorial simplicity, en Psychometrika, 39/1 (1974).

- LAWSHE, C., A quantitative approach to content validity, in Personnel Psychology, 28/4 (1975).

- LELANCHON, L., La reforma del estatuto jurídico civil de los animales en el Derecho francés, en dA.Derecho Animal (Forum of Animal Law Studies) 9/3 (2018). https://doi.org/10.5565/rev/da.344

- LEYTON DONOSO, F., Los animales en la bioética: tensión en las fronteras del antropocentrismo (Barcelona 2019).

- LOEWE HENNY, D. H., Integración de los animales no humanos en la comunidad política: zoopolis, en Revista Chilena de Derecho Animal, 1 (2020).

- LÓPEZ DE LA OSA ESCRIBANO, P., El Derecho del Bienestar Animal en Europa y Estados Unidos (Navarra 2012).

- MONTES FRANCESCHINI, M., Derecho Animal en Chile (Santiago 2018).

- MOORE, P, Majority Endorse Animal Rights, en YouGov (2015). https://today.yougov.com/topics/lifestyle/articles-reports/2015/04/29/majority-endorse-animalrights

- NUNNALLY, J. C., y BERNSTEIN, I. H., Psychometric Theory (New York 1994). 
- NUSSBAUM, M. C., Frontiers of Justice (Cambridge 2006).

- PEDROSA, I., SUÁREZ-ÁLVAREZ, J. y GARCÍA-CUETO, E., Evidencias sobre la validez de contenido: Avances teórico y métodos para su estimación, en Acción Psicológica, 10/2 (2013).

- PHILliPS, C. J. C., IZMIRLI, S., ALDAVOOD, S. J., ALONSO, M., CHOE, B. I., HANLON, A., HANDZISKA, A., ILLMAN, G., KEELING, J., KENNEDY, M, LEE, G. H., LUND, V., MEJDELL, C., PELAGIC, V. R. Y REHN, T., Students' attitudes to animal welfare and rights in Europe and Asia, en Animal Welfare-The UFAW Journal, 21/1 (2012).

- POCAR, M., Los animales no humanos. Por una sociología de los derechos (Buenos Aires 2013).

- REGAN, T., The Case for Animal Rights (Berkeley 1983).

- REY PÉREZ, J. L., El enfoque político de los derechos de los animales desde la teoría de los derechos, en Revista Iberoamericana de Bioética, 4 (2017). https://doi.org/10.14422/rib.i04.y2017.002

- RIFFKIN, R., In US, more say animals should have same rights as people, en Gallup Social Issues, 18 (2015). https://news.gallup.com/poll/183275/say-animals-rights-people.aspx

- RÚA SERNA, J. C., De garras y de guerras: reflexiones sobre el uso de los animales en el ejercicio legal de la seguridad armada desde una visión abolicionista (Medellín 2017).

- SALAZAR, M. A. Activismo pragmático: animalismo y políticas públicas, en Reflexión Política 21/41 (2019). https://doi.org/10.29375/01240781.3283

- SÁNCHEZ GONZÁLEZ, M. A., El debate ético actual sobre la relación del hombre con los animales, en Los derechos de los animales (Madrid 2002).

- SERRA, J. I., Experimentación con animales, en Manual de Derecho Animal (Buenos Aires 2019).

- SERRA PALAO, P., La incorporación de la ética animal al derecho, en Bioderecho.Es 7 (2019). https://doi.org/10.6018/bioderecho.364561

- SHYAM, G., The legal status of animals: the world rethinks its position, en Alternative Law Journal 40/4 (2015). https://doi.org/10.1177/1037969X1504000411

- SHYAM, G., Is the classification of animals as property consistent with modern community attitudes?, en University of New South Wales Law Journal 41/4 (2018).

- SHYAM, G., How community attitudes can strengthen arguments for changing the legal status of animals, en Society Register 3/3 (2019). https://doi.org/10.14746/sr.2019.3.3.04

- SINGER, P., Animal Liberation: a new ethics for our treatment of animals (New York 1975).

- SQUELLA NARDUCCI, H. Introducción al Derecho (Santiago 2014).

- TAI LE, L. y SABATÉ, J., Beyond meatless, the health effects of vegan diets: findings from adventist cohorts, en Nutrients 6 (2014), 2131-2147. https://doi.org/10.3390/nu6062131

- TIRADO, C. R., La dimensión política de las éticas animales en el contexto de la bioética: problemas de integración y desafíos futuros, en Revista Iberoamericana de Bioética 1 (2016). https://doi.org/10.14422/rib.i01.y2016.005

- VÁZQUEZ, R. y VALENCIA, Á., La creciente importancia de los debates antiespecistas en la teoría política contemporánea: del bienestarismo al abolicionismo, en Revista Española de Ciencia Política 42 (2016). https://doi.org/10.21308/recp.42.06

- VIGORITO, M., An animal rights attitude survey of undergraduate psychology students, en Psychological Reports 79 (1996). https://doi.org/10.2466/pr0.1996.79.1.131

- WISE, S., Sacudiendo la jaula: hacia los derechos de los animales (Valencia 2018).

\section{Jurisprudencia}

- CÁMARA FEDERAL DE CASACIÓN PENAL (SEGUNDA SALA). 18 de diciembre de 2014. Causa N ${ }^{\circ}$ CCC 688312014 CFC1 "Orangutana Sandra s/ recurso de casación s/ habeas corpus".

- PRIMER JUZGADO CORRECCIONAL DE LA TERCERA CIRCUNSCRIPCIÓN JUDICIAL. 20 de abril de 2015. Sentencia No 1927, autos No 36.598 caratulados "F. C/ S.R.M.R. P/ maltrato y crueldad animal".

- TERCER JUZGADO DE GARANTÍAS DE MENDOZA. 03 de noviembre de 2016. Expediente P72254/15. "Asociación de funcionarios y abogados por los derechos de los animales y otros contra GCBA sobre amparo". 


\section{Anexo: Escala de percepciones acerca del estatus jurídico atribuido a los animales no humanos}

Instrucciones: A continuación encontrarás una serie de preguntas relacionadas con cómo percibes el estatus jurídico atribuido a los animales no humanos. Para ello, solicitamos responder con sinceridad el grado de acuerdo o desacuerdo ante cada ítem, considerando la siguiente escala:

\begin{tabular}{|c|c|c|c|c|c|c|}
\hline 1 & 2 & 3 & 4 & 5 & 6 & 7 \\
\hline $\begin{array}{c}\text { Totalmente } \\
\text { en } \\
\text { desacuerdo }\end{array}$ & $\begin{array}{c}\text { No estoy de } \\
\text { acuerdo }\end{array}$ & $\begin{array}{c}\text { Algo en } \\
\text { desacuerdo }\end{array}$ & $\begin{array}{c}\text { Ni de } \\
\text { acuerdo ni } \\
\text { en } \\
\text { desacuerdo }\end{array}$ & $\begin{array}{c}\text { Un poco de } \\
\text { acuerdo }\end{array}$ & De acuerdo & $\begin{array}{c}\text { Totalmente } \\
\text { de acuerdo }\end{array}$ \\
\hline
\end{tabular}

\section{Percepciones ético-jurídicas acerca de los animales no humanos en general}

1.1 Los animales deben ser considerados como un fin en sí mismos.

1.2 Los animales no deben ser usados para satisfacer necesidades de los seres humanos.

1.3 Se debe reconocer jurídicamente que los animales están dotados de dignidad.

1.4 Los animales deben tener derechos en sentido jurídico.

1.5 Los animales deben ser titulares de derechos básicos o fundamentales.

1.6 Deben existir mecanismos de tutela o protección ante la vulneración de los derechos de los animales.

1.7 Los derechos de los animales deben tener el mismo valor o importancia jurídica que los derechos de los seres humanos.

1.8 El daño hacia los animales no debe justificarse aún cuando se trate de satisfacer necesidades humanas (ej. alimentación, experimentación, etc).

\section{Percepciones acerca de los derechos de los animales no humanos según su destino atribuido}

2.1. Los derechos de los ANIMALES CON LOS QUE CONVIVIMOS deben tener el mismo valor o importancia jurídica que los derechos de los seres humanos.

2.2. Los derechos de los ANIMALES DESTINADOS PARA ALIMENTACIÓN deben tener el mismo valor o importancia jurídica que los derechos de los seres humanos.

2.3. Los derechos de los ANIMALES DESTINADOS PARA VESTIMENTA deben tener el mismo valor o importancia jurídica que los derechos de los seres humanos.

2.4. Los derechos de los ANIMALES DESTINADOS PARA ESPECTÁCULOS deben tener el mismo valor o importancia jurídica que los derechos de los seres humanos.

2.5. Los derechos de los ANIMALES DESTINADOS PARA TRABAJO deben tener el mismo valor o importancia jurídica que los derechos de los seres humanos.

2.6. Los derechos de los ANIMALES DESTINADOS PARA TESTEO INDUSTRIAL Y COSMÉTICO deben tener el mismo valor o importancia jurídica que los derechos de los seres humanos.

2.7. Los derechos de los ANIMALES DESTINADOS PARA EXPERIMENTACIÓN BIOMÉDICA deben tener el mismo valor o importancia jurídica que los derechos de los seres humanos.

2.8. Los derechos de los ANIMALES SILVESTRES QUE VIVEN EN ESPACIOS URBANOS deben tener el mismo valor o importancia jurídica que los derechos de los seres humanos.

2.9. Los derechos de los ANIMALES SALVAJES deben tener el mismo valor o importancia jurídica que los derechos de los seres humanos.

3. Aceptación de la satisfacción de necesidades humanas según destino distribuido a animales no humanos.

3.1. Los ANIMALES CON LOS QUE CONVIVIMOS no deben ser usados para satisfacer necesidades de los seres humanos.

3.2. Los ANIMALES DESTINADOS PARA ALIMENTACIÓN no deben ser usados para satisfacer necesidades de los seres humanos. 
3.3. Los ANIMALES DESTINADOS PARA VESTIMENTA no deben ser usados para satisfacer necesidades de los seres humanos.

3.4. Los ANIMALES DESTINADOS PARA ESPECTÁCULOS no deben ser usados para satisfacer necesidades de los seres humanos.

3.5. Los ANIMALES DESTINADOS PARA TRABAJO no deben ser usados para satisfacer necesidades de los seres humanos.

3.6. Los ANIMALES DESTINADOS PARA TESTEO INDUSTRIAL Y COSMÉTICO no deben ser usados para satisfacer necesidades de los seres humanos.

3.7. Los ANIMALES DESTINADOS PARA EXPERIMENTACIÓN BIOMÉDICA no deben ser usados para satisfacer necesidades de los seres humanos.

3.8. Los ANIMALES SILVESTRES QUE VIVEN EN ESPACIOS URBANOS no deben ser usados para satisfacer necesidades de los seres humanos.

3.9 Los ANIMALES SALVAJES no deben ser usados para satisfacer necesidades de los seres humanos. 